\title{
11 French Politicians on Facebook and Twitter. Revitalizing political
} representation? - Christophe Leclerc

\subsection{Introduction}

In contrast to the previous contribution, this paper tackles the issue of transparency and social media with a more national perspective. By looking at French deputies posts on Facebook and Twitter, but also by directly inquiring how French citizens assess the issue of political transparency on social media, this analysis aims at providing new insights into the issue as to whether the presence of politicians on social media can affect power relations between citizens and politicians. The underlying rationale is to find out whether this form of transparency ultimately enhances representative democracy.

Over the last decades transparency has often been depicted as the ultimate remedy for various political, economic and societal problems. Stiglitz (1999; 2000; 2002) outlines the significance of transparency for averting market failures and enhancing public financing. Similarly, Lindstedt and Naurin (2010) investigate the capacity of transparency to reduce corruption and achieve fairer and more efficient governance, while Schultz and Kenneth (1998) analyse how better means of communication and transparency can diminish risks of war and international conflicts. Recent cases and scandals have added fuel to debates about transparency. The Luxleaks affair revealed the need for more transparency with regard to existing tax schemes for multinational companies (Gotev, 2015). The opacity of the TTIP negotiations has made experts and citizens suspicious regarding the content of this trading agreement and signal the risk of lowering safety standards and endangering customers' safety (Crisp, 2015). 
If we turn to the realm of politics, we quickly notice that the relationship between transparency and democracy has provoked intense and convoluted debates. Is transparency of governments a necessary feature of democratic regimes? Or, is transparency a political key for better governance? In his succinct definition of democracy, Schumpeter (1942) did not yet consider transparency as an inherent and essential characteristic of democratic regimes. Democracy, he argues, is only determined by the electoral competition and free elections. By contrast, Dahl (1971) - with his famous concept of Poliarchy - places transparency at the core of the democratic framework. As he claims, a democratic regime is not only a regime in which electors have the right to freely vote for their future representatives and governments, it is also a system that allows its citizens to be fully informed - by different and independent sources of information before they cast their ballot. This implies a free and transparent flow of information.

The recent legitimacy crisis affecting many Western democracies, has given new impetus to pro-transparency arguments. In a society where citizens are slowly disengaging from politics, many experts and politicians argue, greater transparency and accountability in politics are the best options available to revitalize representative democracy. Making use of new means of communication, several European governments - including the European Union -have recently taken measures to improve oversight over politicians and big companies' financial and fiscal activities ("European Commission presents", 2015; Bekmezian, 2013). Moreover, many local and national politicians are now trying to share their opinions and activities on social media with the goal of restoring the dialogue with their electorate. In the light of this recent trend of developments, this paper examines the use of Facebook and Twitter's by French politicians, and addresses the following 
research question "Does transparency through social media succeed in reconnecting French representatives with their citizens?"

This paper concentrates on France for two main reasons. Firstly, with only $17 \%$ of French citizens trusting their own government, and $24 \%$ trusting the French "Assemblée Nationale", France is today one of the most distrustful European countries with regard to its national institutions (Eurobarometer, 2014). It is highly relevant, therefore, to ask whether the presence of French representatives on social media can bridge the growing gap and help overcoming the crisis of political legitimacy. Secondly, since most existing studies on the topic have exclusively focused on the United States, it is high time to look at a different case.

The focus on Facebook and Twitter can be justified by two arguments. With approximatively 1,415 billion of people using Facebook and 288 million of people on Twitter, these two platforms are among the most widely used social networks worldwide today ("Leading Social Networks", 2015). Additionally, the design of Facebook and Twitter's, based on easy and direct interaction between users, is especially appropriate to analyze political debates.

This paper claims that, although French politicians widely use Facebook and Twitter, their attempts to re-engage citizens in politics frequently remain futile. In other words, even though a lot of information is shared on social media, only a small part of the population takes the time to consult it.

In order to answer my research question this chapter builds its analysis around two main axes. In the first part, it examines to which extent French deputies are using Facebook and Twitter and evaluates the nature of their activities on these social networks. Furthermore, in a second part, the chapter looks at how citizens judge the attempt to enhance transparency 
through social media and sheds light on whether people use communication through social media to be informed about the opinions and activities of political figures.

\subsubsection{State of the art: Understanding transparency in the frame of political} representation

Representative democracy is the cornerstone of modern Western societies. Although the idea of representative democracy goes almost unchallenged, trying to define and understand what democracy represents can sometimes appear to be quite puzzling.

For Jean Jacques Rousseau (1762), political representation is incompatible with the notion of democracy. He argues that popular sovereignty -the general will of the people - cannot be represented because representation necessarily implies alienation. In Rousseau's view, the "deputies of the people" should therefore not be seen as representatives but rather as commissionaires or delegates, deprived of true political will. This vision of direct democracy through political delegation has been widely criticized for its lack of practicality. Before Jean Jacques Rousseau, Montesquieu highlighted the advantages of electing politicians endowed with free mandates. He argues that having independent representatives is the best way to take into consideration the plurality of society and to make laws that are applicable to the general interest of the people (Urbinati, 2006). This line of thinking was further developed by Sieyes who, contesting Rousseau's ideas of direct democracy, raised representative democracy to the norm. Sieyes argued that representative democracy is the only system that provides "authority from the top and confidence from the bottom" (ibid.). 
Today, all Western democracies have adopted a system of political representation in which elected politicians are free to act in accordance to their political views for a limited time span. Urbinati (ibid.) argues that modern representative democracy is somehow situated between Rousseau's rigid view of political delegation, and Sieyes's conception of free mandate. Although political representation does not institute legally binding mandates, it entails a system of check and balances from the citizenry to the representatives. This system of check and balances constitutes a new type of mandate, a political mandate whose currency is both political and ideological. In this context, the representative does not only act on the behalf of his constituents, he must also act in the best interest of the represented. This implies a complex - almost symbiotic - relationship between the voters and the representative through which representative must be constantly in tune with society and vice versa. Such a complex relationship, as suggested in Urbinati's description, requires advanced means of communication between the voter and the representative. It also presupposes an advanced level of transparency, through which citizens can hold their representatives answerable for their actions.

Some scholars (e.g. Mair, 2011; Crouch, 2004) state that the classical conception of political representation has recently been challenged by various trends in modern society. Mair (2011) argues that the development of mass democracy during the 20th century, coupled with the emergence of economic, technological and political globalization, has profoundly changed the nature of politics in Western democracies. In a world becoming more and more complex, and in which an increasing number of national and supranational actors are involved in the process of policy making, it becomes extremely complicated - to not say impossible - for citizens to understand the actions of their representatives. Under such conditions, citizens slowly 
start to drift away from politics, disengaging themselves from any sort of political engagement.

As a consequence of these late developments, modern democrats are calling for ways to transcend traditional forms of political representation and bridge the increasing gap between electors and representatives. Many studies explore the impact of new technologies on representative relations particularly in terms of intensifying transparency (Coleman \& Gotze, 2011; Coleman, 2004; Grossman, L, K, 1996; Becker \& Slaton, 2000). Chadwick (2006) investigates the potential for the creation of common cyber political spaces through which citizens and politicians could efficiently exchange information. Coleman (2005) argues that new technologies offer new ways of communicating and new means of transparency, which could eventually galvanize and redefine the traditional represented/representative relationship. Firstly, better access to information and advanced transparency could hold up the actions and opinions of representatives to public scrutiny. Secondly, new technologies could take away time and space barriers by allowing citizens to instantaneously and transparently contact their representatives, thereby creating a more direct relationship. Robin Cook, leader of the House of Commons, strongly endorsed this view. In 2002 he declared that "new technologies can strengthen our democracy, by giving us greater opportunities than ever before for better transparency and a more responsive relationship between government and electors" (Coleman, 2005: 183, cited after Morris, 2001: 1013).

Initially, however, political elites were not too eager to exploit the full potential of technology. Instead, they were rather halfhearted about the new technology, and did not try to change existing practices (Coleman, 2004, 2005; Jackson, 2005). Only with the advent of social media the opportunities to increase transparency were more fully acknowledged. Today, millions of citizens are connected in a single digital world where 
information moves faster than ever. They share their views on countless numbers of topics, and instantly react to news feeds. Moreover, they have the opportunity to follow their representatives' activities by looking at their Internet pages, on which they can openly address their concerns.

These new trends have only begun to be tackled by academic studies. Although quite a few authors focus on the potential effect of social media on civic and political participation (Zuniga 2012; Vesnic Alusevic, 2012; Gustafson, 2012; Zhang et al, 2008; Leung, 2009), and on their impact on the public sector (Mergel, 2013), only very few have examined the link between transparency through social media and political representation. It is therefore in the aim of filling up this academic gap that this paper aims at exploring to what extent transparency in social media succeeds in bringing together citizens and representatives.

\subsection{Method and data}

In a first part, this paper assesses to which extent social media are today used by French politicians to publicly communicate their actions and whether these pages are commonly visited by social media's users. This study, which only focuses on the cases of Twitter and Facebook, mainly makes use of quantitative and qualitative methods of analysis. To begin with, this paper evaluates the share of deputies that hold an official Facebook or Twitter account in 2015 and, subsequently, when it is the case, looks at their Facebook and Twitter pages in order to retrieve their amount of followers. We decide to divide these Facebook and Twitter pages into five categories: (1) pages having between 0 and 1.000 followers, (2) pages having between 1.000 and 5.000 followers, (3) pages having between 5.000 and 50.000 followers, (4) pages having between 50.000 and 100.000 and (5) pages that have more than 100.000 followers. Following this quantitative examination, this paper selectively focuses on a limited amount of Facebook and Twitter 
accounts. It therefore investigates the type of information shared on these pages, and observes the type of reactions these posts may have triggered. To do so, concerning the Facebook pages, this paper examines in a first time the amount of "like", "share", and "comments" these publications have gathered. Regarding the nature of information they provide, these posts are furthermore divided into three categories. The first category (Opinion) covers opinion articles, opinion status, and other type of political or legislative information. The second category (Activity) involves any type of evidence that may inform citizens on the activities and local actions of their representatives. The third category (Other) brings together information that is not associated with politics. Finally, this paper looks at the amount of direct interactions - direct reply on the Facebook comments box - between followers and owners of these pages. With respect to Twitter pages, the analysis focuses on the amount of "Retweet" and "Favourite" each post generated. These posts are subsequently separated following the same pattern of categories previously used with Facebook pages (Opinion, Activity, Other). Moreover, similarly to the Facebook study, the amount of direct interactions between people and holders of these pages is inspected. Due to the limited scope of this paper, this examination concentrates on one Facebook and one Twitter page per category during a limited time frame of three months - from January to April 2015.

The second part of this research firstly examines whether people actually use social media to oversee the actions of their representative. Furthermore, it sheds light on how people evaluate the efficiency and credibility of this process of political transparency on Twitter and Facebook. In this respect, this paper analyses the results of a survey conducted among 150 French citizens. This survey hence aims at testing two hypotheses; $\mathrm{H} 1$ stating that "a small part of Facebook and Twitter users, use social media to be informed about the political activities of their representatives", and $\mathrm{H} 2$ 
MaRBLE Research Papers | Edition 2016 | Volume III

claiming that "social media has not succeeded in creating a new type of interaction between represented and representatives".

\subsection{Facebook and Twitter: two new transparent platforms used by} representatives to inform their citizens and re-connect with their electorate?

In this section, this paper addresses the issue of transparency of politicians through social media. It analyses, in a first time, to which extent Facebook and Twitter are used by French deputies to share different sort of information with their public. In a second time, it sheds light on the nature of these publications, trying to understand whether they focus on political topics and whether they tend to generate direct interactions with the citizens.

\subsubsection{Assessment of the use of Facebook and Twitter among French deputies}

This analysis begins by examining the propensity of French political representatives - meaning here French deputies - to use Facebook and Twitter. There are at the moment 577 deputies composing the French National assembly. This study examines the case of every single deputy, establishing whether they are active on social media and, if yes, their number of followers.

This examination shows that $77 \%$ (444 deputies) of the French deputies hold an official Facebook page. Out of this $77 \%$, $8 \%$ have however not posted any information since the 1st of January 2015 . These deputies will be assigned to the "Not Active" category from now on (Figure 4.1.1). Concerning Twitter, $72 \%$ (415) of the French deputies possess an official 
Twitter account; among them 4\% are considered not being active (Figure 4.1.1). These numbers indicate that using social media for political purposes is today a widespread behaviour among French representatives. It also suggests that, although French deputies use Facebook and Twitter to a really similar extent, there is biggest tendency of being inactive on Facebook than on Twitter.

Figure 4.1.1: Deputies on Facebook and Twitter

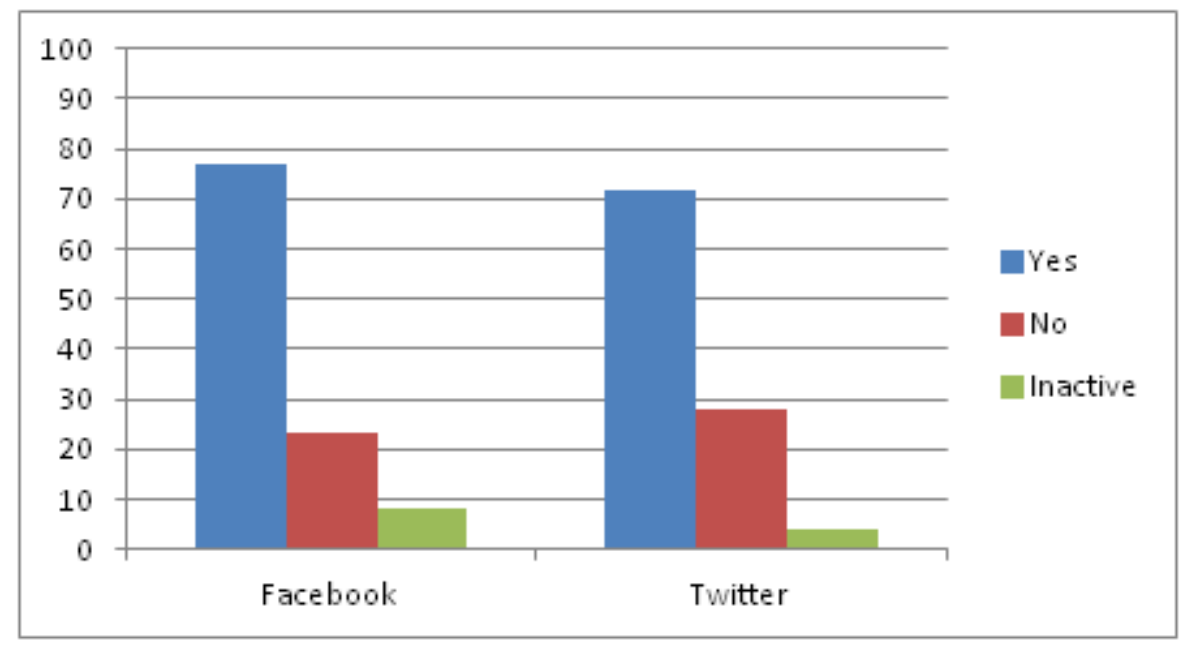

Source: Author's calculation based on Facebook and Twitter's data, 2015.

Yet, even though it seems clear that social media are today regularly used by French political representatives, it is essential to know to which extent these pages are actually being visited by the public. Regarding deputies' Facebook pages, this analysis shows that $40 \%$ of the pages have less than 1.000 followers, $54 \%$ have between 1.000 and 10.000 followers, 
$5 \%$ between 10.000 and $50.000,0.7 \%$ between 50.000 and 100.000 , and only $0.3 \%$ with more than 100.000 followers (Figure 4.1 .2 ). These results appear to be quite different when looking at Twitter pages. As observed in this research, $28 \%$ of deputies' Twitter pages have less than 1.000 followers, $55 \%$ have between 1.000 and 10.000 followers, $11 \%$ between 10.000 and $50.000,4 \%$ between 50.000 and 100.000 and $2 \%$ with more than 100.000 followers (Figure 4.1.2).

Two conclusions can be drawn from this study. First of all, there is a clearer tendency for Facebook pages to have less than 1000 followers than Twitter pages. Second of all, there is a better propensity for Twitter pages to reach really important amounts of followers (more than 10.000). These two elements suggest that Twitter is more commonly used by the public than Facebook when it comes to political issues.

Figure 4.1.2: Deputies on Facebook and Twitter per category

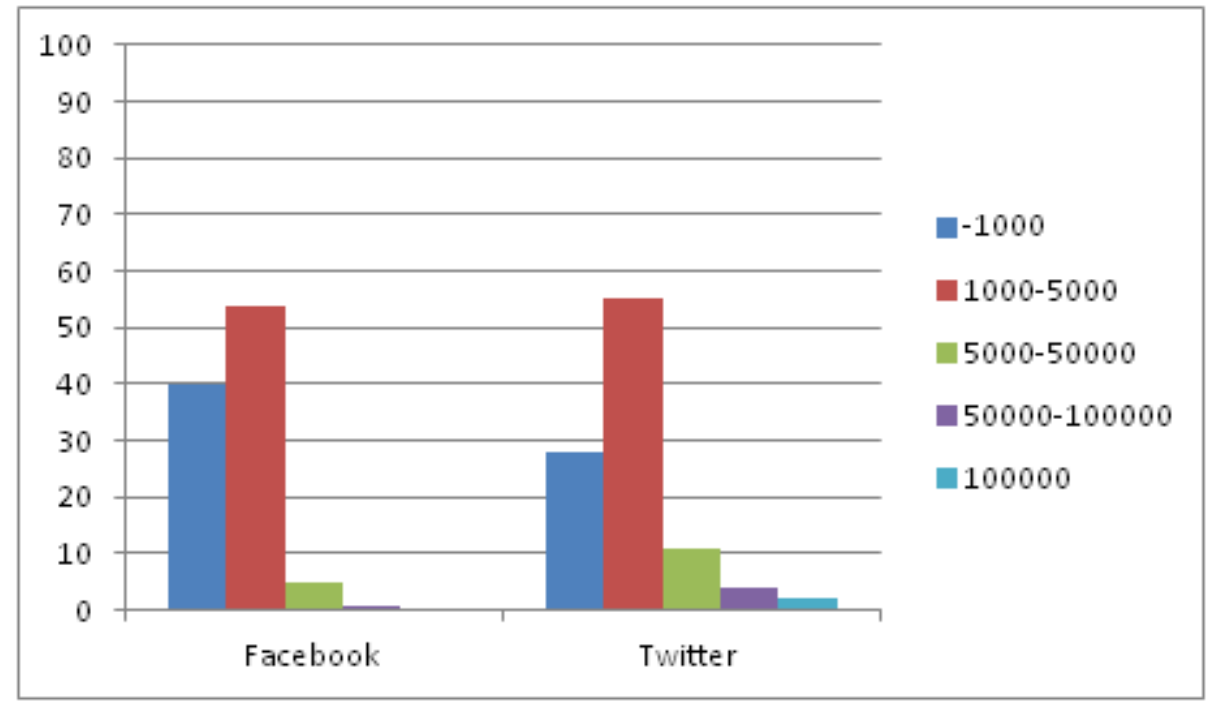

Source: Author's calculation based on Facebook and Twitter's data, 2015.

In conclusion, one can claim that Facebook and Twitter are today extensively used by French deputies for political purposes. Yet, while both 
social networks seem to be used to a similar extent by French representatives, they tend to encounter a contrasted success in terms of Followers. In respect of Facebook, $94 \%$ of the pages examined gather between 0 and 10.000 followers while only $1 \%$ of them are being followed by more than 50.000 people. These are two really low numbers. This situation is however different regarding Twitter pages. Indeed, with only $28 \%$ of pages with less than 1000 followers and $17 \%$ with more than 50.000 , one can argue that Twitter can generally attract a higher number of followers and, therefore, has a better capacity to digitally connect people with their representatives.

\subsubsection{Observing the nature of information and type of interactions: a content} analysis of ten case studies

The second part of this paper intends to shed light on the nature of the information published by the French deputies on Facebook and Twitter and, moreover, on the type of reactions these publications engender. In order to draw a representative picture of the content of these pages, this study investigates ten different case studies. The selection of these cases follows the classification set in the previous section; examining one Twitter and Facebook account per category of followers. These pages are subsequently compared in terms of quantity of publications shared, type of information published, and nature of reactions these publications generate (see section methods and data).

\subsubsection{First category: between 0 to 1000 followers}

Concerning the first category of followers ( 0 to 1000 followers) we investigate the Facebook page of Gilles Savary (227 followers) and the 
Twitter page of Martial Saddier (717 followers). Gilles Savary is the deputy of the 9th district of Gironde and Martial Saddier is the deputy of the 3rd circonscription of Haute-Savoie; both are generally unknown on the national scale. When looking at a quantitative perspective, a first analysis of these two pages shows that an extensively higher amount of information have been published on the Twitter page (237) in comparison with the Facebook page (25) (Figure 4.2.1.1).

Figure 4.2.1.1: Number of publications on Facebook and Twitter

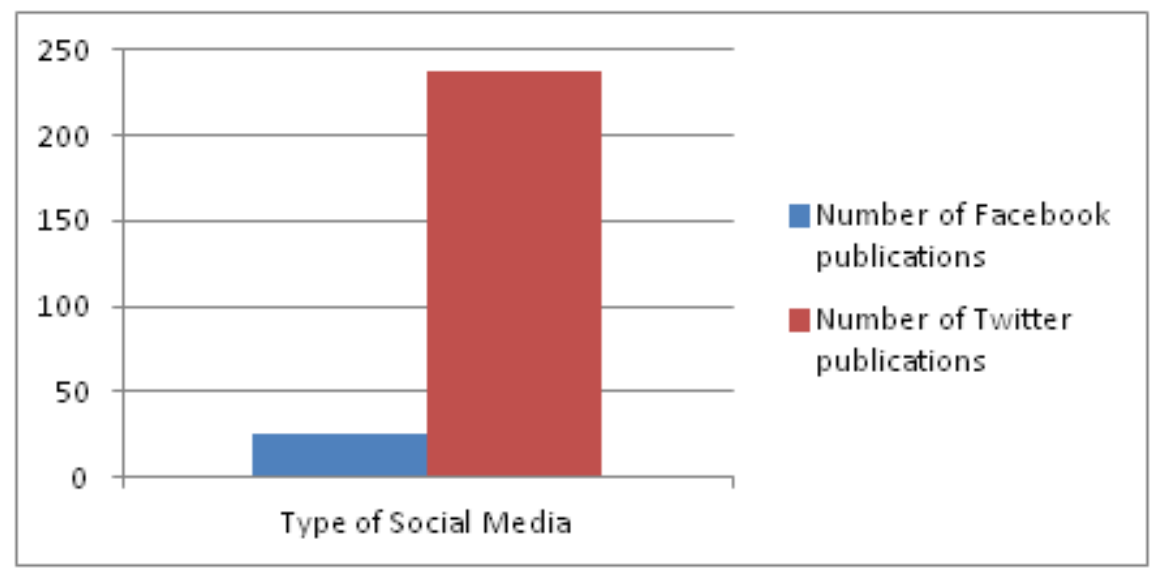

Source: Author's calculation based on Facebook and Twitter's data, 2015.

In regard to the nature of these publications, the results of this research tend to display that a large part of the information shared on these two pages was about political matters. With less than $10 \%$ of the publications classified as "Others" in both cases, most of the information published concerned the activities or the opinion of the deputy (Figure 4.2.1.2).

Figure 4.2.1.2: Type of information published 


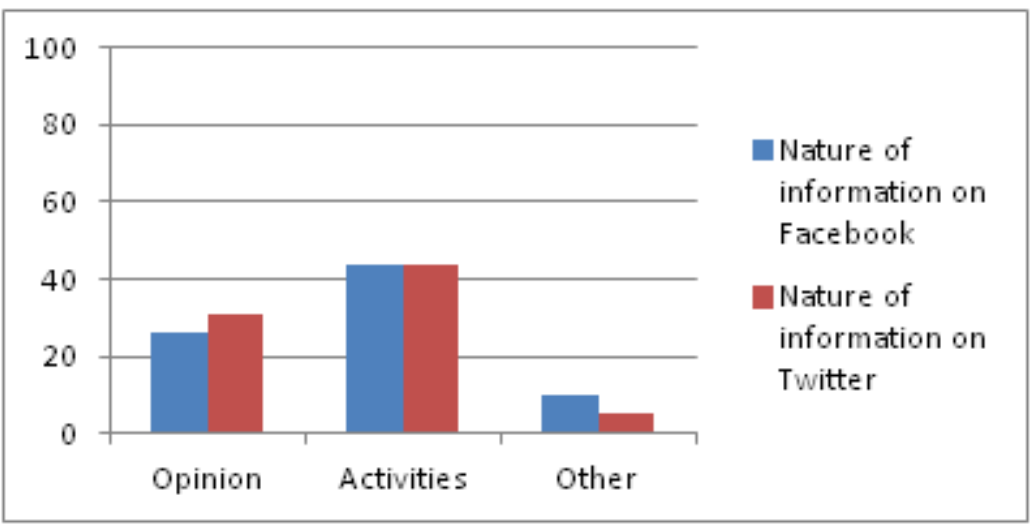

Source: Author's calculation based on Facebook and Twitter's data, 2015.

Comparing these two pages shows that Facebook and Twitter publications bring about really different types of reactions from the public. Following the method previously mentioned in the Method and Data section, this study suggests that, in this case, Facebook posts generate a higher number of reactions from the people (Table 4.2.1.3). A more in-depth investigation of the Facebook and Twitter comments indicates that comments and discussions often tend to be more constructive and less vulgar on Facebook than on Twitter. Furthermore, it is interesting to observe that, with the exception of two or three cases, almost none of these comments or reactions have revealed direct discussions or interactions between the holder of the page and the public.

Table 4.2.1.3: Type and number of follower's reactions

\begin{tabular}{|l|l|}
\hline Type of reactions (Facebook) & Average number of reactions \\
\hline "Like" & 31 \\
\hline "Share" & 4 \\
\hline
\end{tabular}


MaRBLE Research Papers | Edition 2016 | Volume III

\begin{tabular}{|l|l|}
\hline "Comment" & 5 \\
\hline
\end{tabular}

\begin{tabular}{|l|l|}
\hline Type of reactions (Twitter) & Average number of reactions \\
\hline "Retweet" & 3 \\
\hline "Favourite" & 0.5 \\
\hline "Comment" & 1 \\
\hline
\end{tabular}

Source: Author's calculation based on Facebook and Twitter's data, 2015.

\subsubsection{Second category: between 1.000 and 10.000 followers}

This section focuses on the Facebook and Twitter pages of the deputy Laurent Baumel (Facebook: 5403 followers; Twitter: 5233 followers). Laurent Baumel is the former mayor of Ballan-Miré and is currently the deputy of the 4th district of Indre-et-Loire. Member of the Partie Socialiste, he is quite renowned locally but remains rather unknown to the French general public. Similarly to the precedent case, our examination shows that more information were released on the Twitter page (73) than on the Facebook one (48) - however with a lower differential between the two (Figure 4.2.2.1).

Figure 4.2.2.1: Number of publications on Facebook and Twitter 
MaRBLE Research Papers | Edition 2016 | Volume III

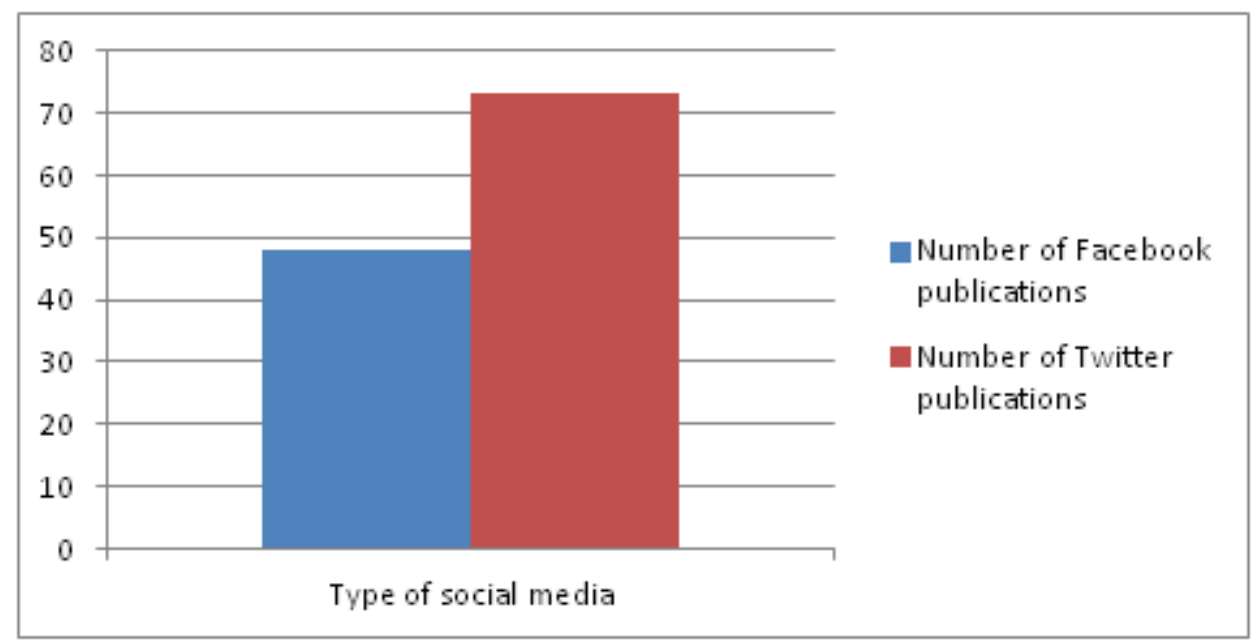

Source: Author's calculation based on Facebook and Twitter's data, 2015.

With $8 \%$ of the Facebook posts and $22 \%$ of the Twitter publications qualified as "Others", one can argue that a great part of these publications is moreover related to political issues; either explaining representatives' activities or opinion. This confirms our previous findings and indicate that most of the information shared by the deputies addresses political questions (Figure 4.2.2.2).

Figure 4.2.2.2: Type of information published

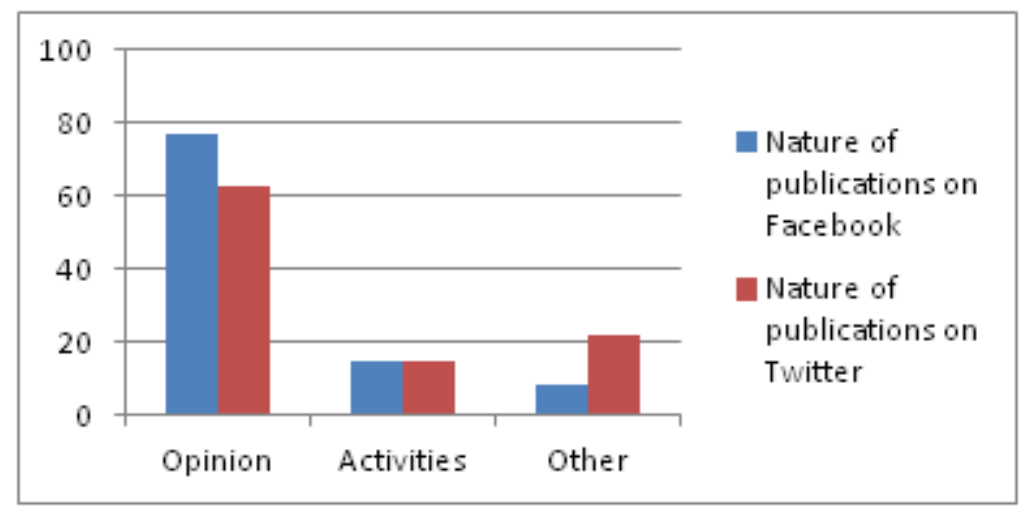

Source: Author's calculation based on Facebook and Twitter's data, 2015. 
Regarding reactions to these Facebook and Twitter posts, it is significant to point out that, here again, Facebook posts triggered more reactions than Twitter publications (Table 4.2.2.3). A large majority of Twitter comments was revealed to be insulting and highly offensive, whereas Facebook discussions were again more fruitful for dialogue. However, only a few numbers of these discussions actually involved a direct interaction between the followers and the owner of these two pages.

Table 4.2.2.3: Type and Number of followers' reactions

\begin{tabular}{|l|l|}
\hline Type of reactions (Facebook) & Average number of reactions \\
\hline "Like" & 26 \\
\hline "Share" & 5 \\
\hline "Comment" & 4 \\
\hline
\end{tabular}

\begin{tabular}{|l|l|}
\hline Type of reactions (Twitter) & Average number of reactions \\
\hline "Retweet" & 5 \\
\hline "Favourite" & 2 \\
\hline "Comment" & 5 \\
\hline
\end{tabular}

Source: Author's calculation based on Facebook and Twitter's data, 2015. 


\subsubsection{Third category: between 10.000 and 50.000 followers}

This third section examines the case of the Facebook and Twitter pages of the French deputy Frank Riester (Facebook page: 12482 followers. Twitter page: 21.100 followers). Frank Riester is the incumbent mayor of Coulommiers and current deputy of the 5th district of Seine-et-Marne. Member of the newly created movement "Les Republicains" - formerly named UMP - he is sometimes considered as being one of the future leaders of the French right-wing movement. Analysing these two pages, firstly indicates that a higher amount of information is published on Twitter (110 publications) than on Facebook (40 publications) between January and May 2015 (Figure 4.2.3.1). 80\% of these publications is moreover classified in both cases as either "Opinion" or "Activities", thus leaving only $20 \%$ in the "Others" category. This corroborates our previous results (Figure 4.2.3.2).

Figure 4.2.3.1: Number of publications on Facebook and Twitter

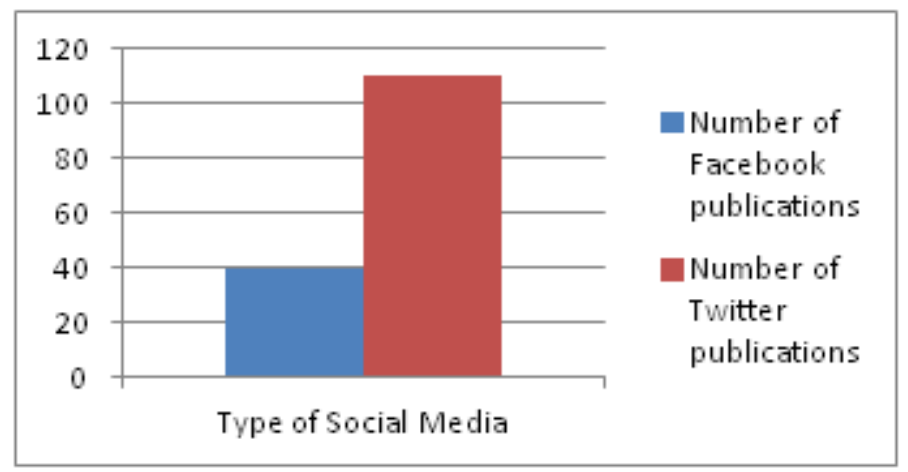

Source: Author's calculation based on Facebook and Twitter's data, 2015. 
Figure 4.2.3.2: Type of information

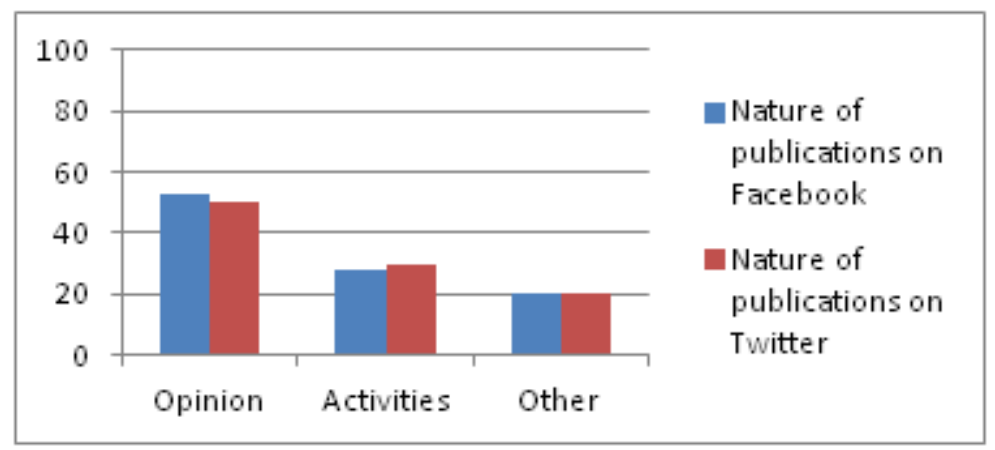

Source: Author's calculation based on Facebook and Twitter's data, 2015.

Finally, in regard to the type of reactions, this examination confirms that Facebook posts have a strong tendency to generate more reactions from the public (Table 4.2.3.3). These reactions appear to be undoubtedly more positive and respectful on Facebook than on Twitter. Yet, here again, they only provoke a really limited number of direct interactions between represented and representative. 
Table 4.2.3.3. Type and number of followers' reactions

\begin{tabular}{|l|l|}
\hline Type of reactions (Facebook) & Average number of reactions \\
\hline "Like" & 75 \\
\hline "Share" & 2 \\
\hline "Comment" & 7 \\
\hline
\end{tabular}

\begin{tabular}{|l|l|}
\hline Type of reactions (Twitter) & Average number of reactions \\
\hline "Retweet" & 5 \\
\hline "Favourite" & 2 \\
\hline "Comment" & 6 \\
\hline
\end{tabular}

Source: Author's calculation based on Facebook and Twitter's data, 2015.

\subsubsection{Fourth category: between 10.000 and 50.000 followers}

Regarding the fourth category, this study looks at the Facebook page of François Fillon (63.803 followers) and the Twitter page of Marion Maréchal 
Le Pen (61.900 followers). François Fillon is the deputy of the 2nd district of Paris. He is one of the leaders of the French right wing party "Les republicains". Marion Maréchal Le Pen is the deputy of the 3rd district of Vaucluse. Being the granddaughter of Jean Marie Le Pen, and niece of Marine Le Pen, she is often described as the new rising figure of the extreme right party "Front National". In respect to the number of Facebook and Twitter publications, a first observation of these two pages shows that, while only 77 post were shared on François Fillon's Facebook page, 1250 posts were published on Marion Marechal Le Pen 's Twitter page (Figure 4.2.4.1).

Figure 4.2.4.1: Number of Facebook and Twitter publications

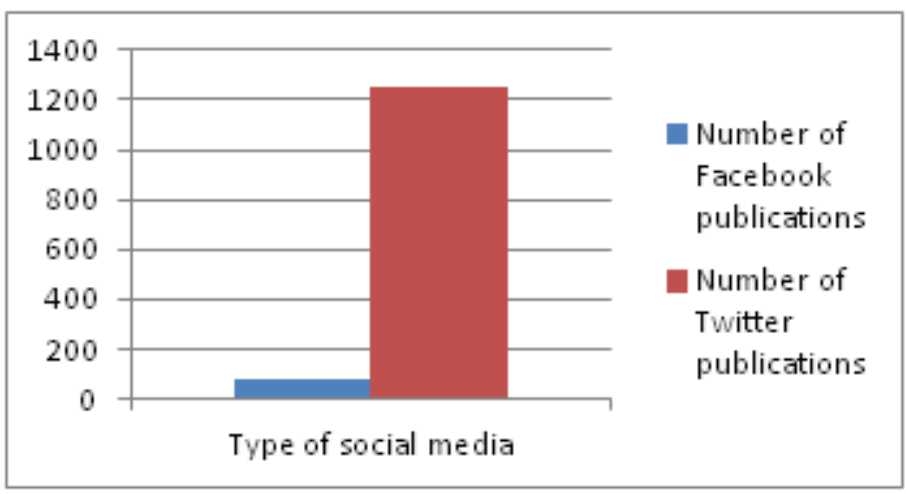

Source: Author's calculation based on Facebook and Twitter's data, 2015.

Looking at the nature of these Facebook and Twitter publications indicates that only $13 \%$ of Facebook posts and $8 \%$ of Twitter publications fit into the category "Other". Thus, one can claim that both Facebook and Twitter pages mainly aimed at informing the public about the opinion or the activity of the deputy under consideration (Figure 4.2.4.2)

Figure 4.2.4.2: Type of information 
MaRBLE Research Papers | Edition 2016 | Volume III

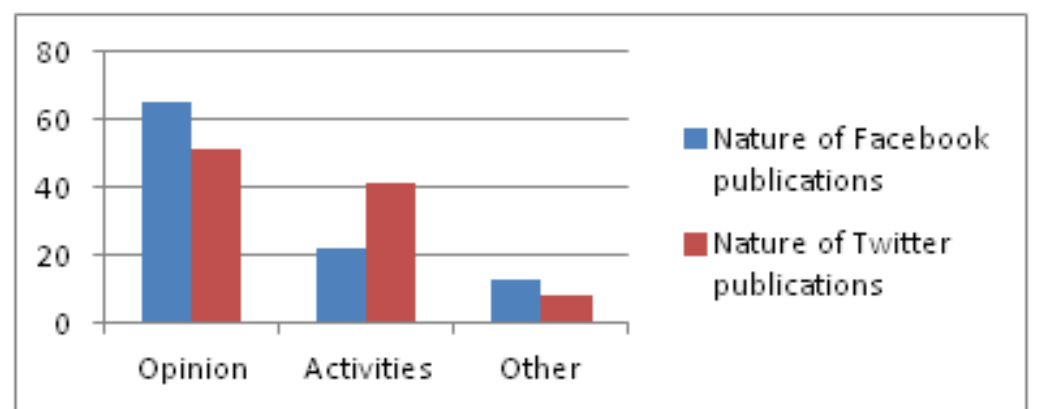

Source: Author's calculation based on Facebook and Twitter's data, 2015.

Furthermore, a last glance over these pages reveals that Facebook posts initiate more public reactions than Twitter publications in terms of "Like", "Share", "Retweet", and "Favourite" (Table 4.2.4.3). The situation is however relatively different regarding the comments left by users of these pages. Moreover, comments and discussions are in general more productive and meaningful on Facebook than on Twitter. These different reactions however did not generate any direct interactions between social media users and their representatives.

Table 4.2.4.3: Type and number of followers' reactions

\begin{tabular}{|l|l|}
\hline Type of reactions (Facebook) & Average number of reactions \\
\hline "Like" & 571 \\
\hline "Share" & 60 \\
\hline "Comment" & 35 \\
\hline
\end{tabular}


MaRBLE Research Papers | Edition 2016 | Volume III

\begin{tabular}{|l|l|}
\hline Type of reactions (Twitter) & Average number of reactions \\
\hline "Retweet" & 152 \\
\hline "Favourite" & 51 \\
\hline "Comment" & 77 \\
\hline
\end{tabular}

Source: Author's calculation based on Facebook and Twitter's data, 2015.

\subsubsection{Fifth category: more than 100.000 followers}

For this last category, this section concentrates on the Facebook page of Marion Marechal Le Pen (240. 210 followers) and the Twitter page of François Fillon (233. 000 followers). A higher number of publications was released on François Fillon's Twitter page compared to Marion Marechal Facebook page (Figure 4.2.5.1).

Figure 4.2.5.1: Number of Facebook and Twitter's publications

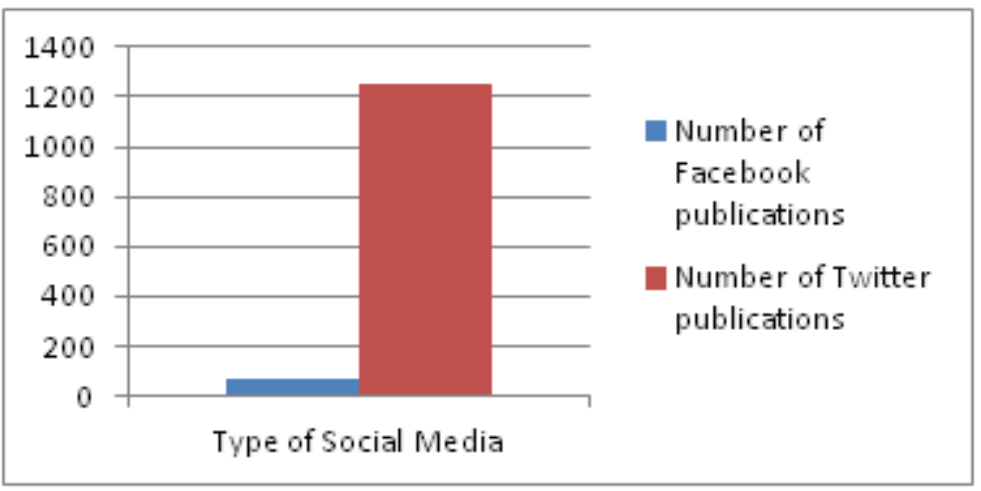

Source: Author's calculation based on Facebook and Twitter's data, 2015. 
Moreover, $8 \%$ of the information shared on Marion Marechal Le Pen's Twitter page is labelled as "Others". This number appears to be higher in the case of François Fillon's Facebook page - 22\% of the publication being characterized as "Others" (Figure 4.2.5.2). Yet, one can argue that a large share of the information disclosed on these two pages communicates about the political agendas of the two deputies.

Figure 4.2.5.2. Type of publications

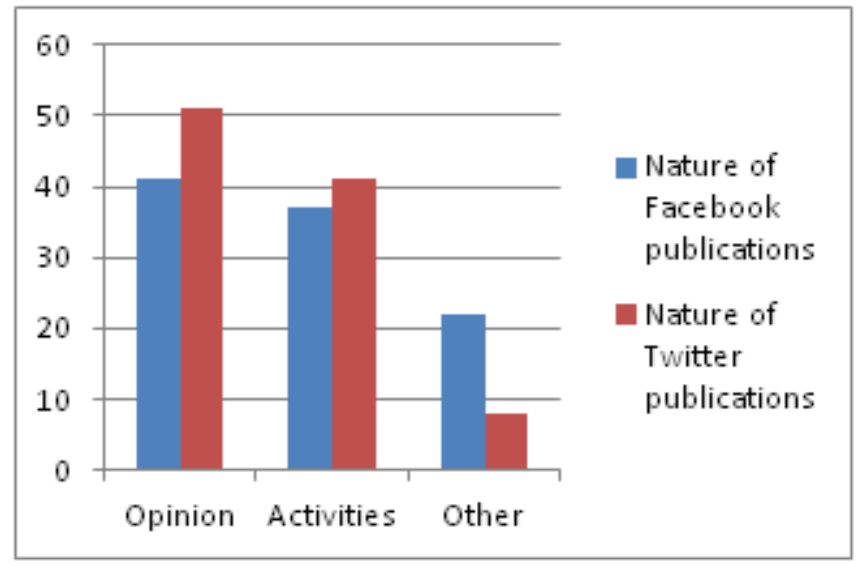

Source: Author's calculation based on Facebook and Twitter's data, 2015.

The examination of the type and number of followers' reactions suggests that, once again, Facebook publications have a tendency to generate more reactions from the public, once again, with more constructive discussions started on Facebook, and no direct interactions (Table 4.2.5.3). 
MaRBLE Research Papers | Edition 2016 | Volume III

Table 4.2.5.3. Type and number of followers' reactions

\begin{tabular}{|l|l|}
\hline Type of reactions (Facebook) & Average number of reactions \\
\hline "Like" & 8832 \\
\hline "Share" & 537 \\
\hline "Comment" & 589 \\
\hline
\end{tabular}

\begin{tabular}{|l|l|}
\hline Type of reactions (Twitter) & Average number of reactions \\
\hline "Retweet" & 30 \\
\hline
\end{tabular}




\begin{tabular}{|l|l|}
\hline "Favourite" & 10 \\
\hline "Comment" & 82 \\
\hline
\end{tabular}

Source: Author's calculation based on Facebook and Twitter's data, 2015.

To conclude, these findings indicate that a really large part of the publications shared by politicians on Facebook and Twitter are about political issues. These publications tend moreover to generate relatively high number of reactions on both platforms - although this number is generally more important on Facebook than on Twitter. However, looking at followers reactions teaches us that a lot needs to be done before to fully transform social media into a new type of electronic democratic consilium in which represented and representatives could freely exchange opinions and information. Although some Facebook discussions appeared to be rather constructive and purposeful, people's reactions - most particularly on Twitter - were in general relatively aggressive and insulting. Moreover, with the exception of a few cases, only a really low number of these discussions actually involved direct dialoguing between the deputies and the public.

\subsection{Looking at the other side: an analysis of the impact of transparency in social} media on French citizens

After having analysed the propensity of French deputies to use social media as a new transparent and democratic tool, this paper now looks at the other side of the mirror; assessing how people actually evaluate this process. We considered that the best way to calculate such an elusive type of information 
was to conduct a survey among French citizens. This survey aims at testing two distinguishable, albeit complementary, hypotheses. The first hypothesis $\mathrm{H} 1$ establishes that "a small part of French citizens use social media to learn more about the opinions and activities of their representatives". The second hypothesis $\mathrm{H} 2$ states that "social media has not succeeded in informing the public and in creating a new type of interaction between represented and representatives".

11.4.1 Testing the first hypothesis (H1): to which extent do people use social media with the goal of being informed about their representatives' activities and opinions?

The following part aims at testing our first hypothesis $(\mathrm{H} 1)$; "a small part of French citizens use social media to learn more about the opinions and activities of their representatives". In order to obtain a first outline of the situation, we start off our questionnaire with two rather simple and straightforward questions; Q1 "Are you a user of Facebook?"; Q2 "Are you a user of Twitter?". We observe that most of the people surveyed declared to belong to the Facebook community (Yes: 87\%, No: 13\%), whereas only $23 \%$ of them are users of Twitter (Figure 5.1.1)

Figure 5.1.1: Percentage of French citizens using Facebook or Twitter 


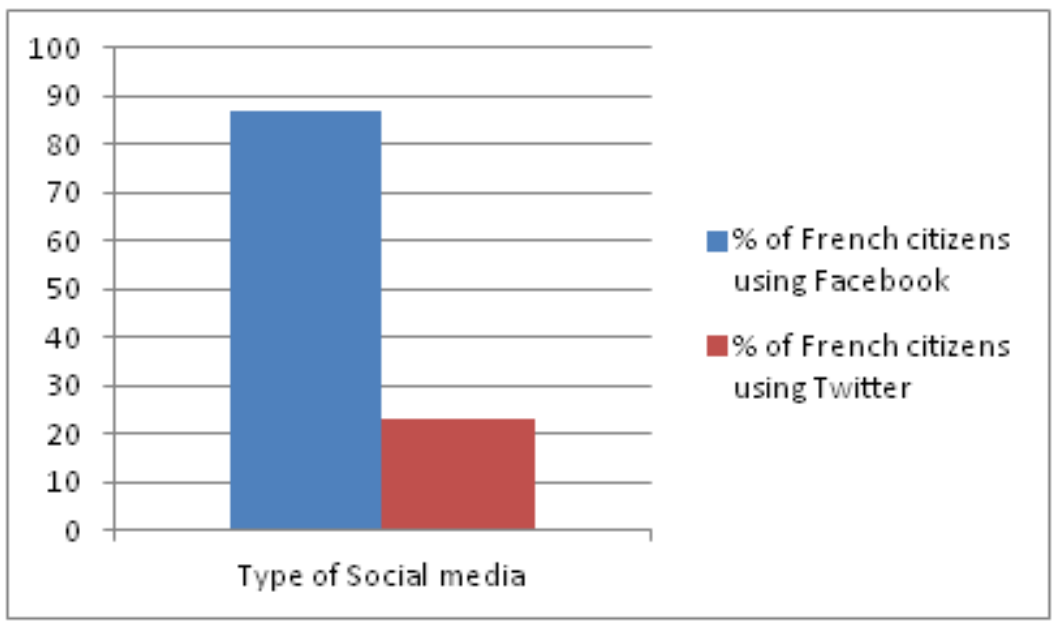

Source: Author

We then decide to firstly extend and deepen this analysis by asking the people surveyed whether they follow political figures on Facebook (Q3) or Twitter (Q4), and if yes, the frequency with which they consult these pages (Q5; Q6). To the question "Do you follow political figures on Facebook?" 28.5\% of the people answered with a "Yes" (Figure 5.1.2). A breakdown of these results shows that most of the people actually claim to follow international or national political figures, only $3.5 \%$ of them actually declaring to follow their local deputy (Figure 5.1.3). Regarding Twitter, our results display that $43 \%$ of the people surveyed follow one or several political figures (Figure 5.1.4). Moreover, similar to the previous case, most of the respondents declare to follow either an International politician (50\%) or a French national political figure ( $42 \%$ ). Only $8 \%$ disclose to follow a politician of the European Union and none of them have actually "befriended" their local deputy (Figure 5.1.5). We further expand this study by assessing how many times our respondents tend to visit these Facebook (Q7) and Twitter pages (Q8) per week. In respect of Facebook pages, a majority of the people surveyed admitted to visit them less than one week $(43 \%) ; 13 \%$ visit them two of three times a week, $24 \%$ once a week, and 
MaRBLE Research Papers | Edition 2016 | Volume III

only $20 \%$ consult them everyday (Figure 5.1.6). Likewise with Facebook, a majority of Twitter's users go on these pages less than one week (33\%) when only a minority check them everyday (13\%) (Figure 5.1.6).

Figure 5.1.2. Percentage of people following political figures on Facebook

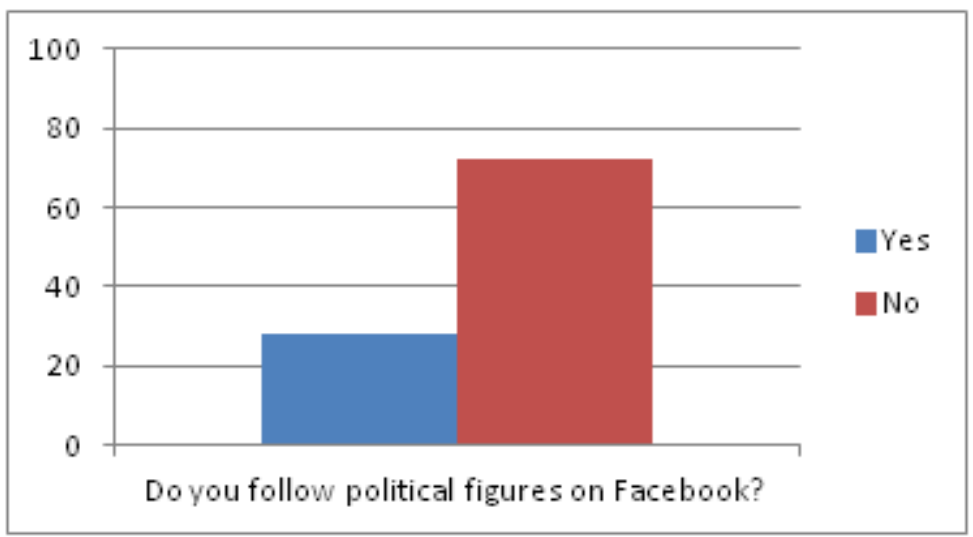

Source: Author

Figure 5.1.3. Nature of the political figures being followed on Facebook

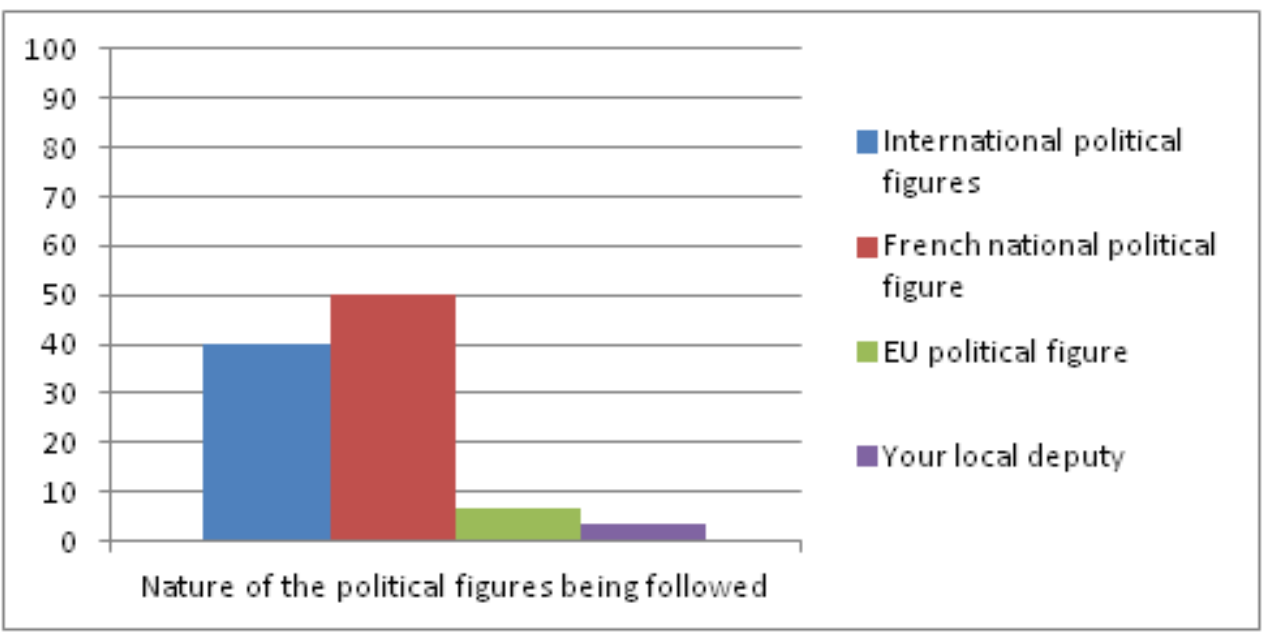

Source: Author

Figure 5.1.4. Percentage of people following political figures on Twitter 
MaRBLE Research Papers | Edition 2016 | Volume III

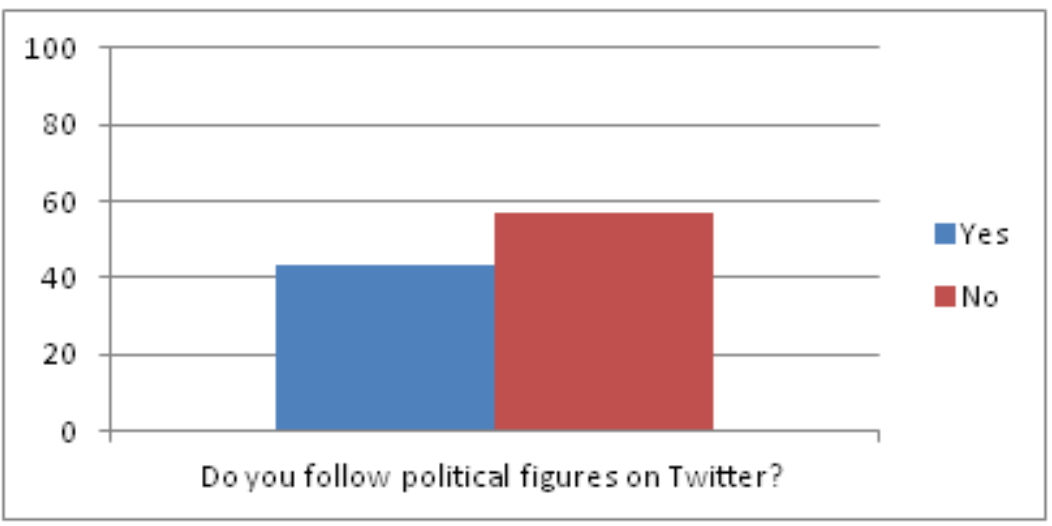

Source: Author

Figure 5.1.5. Nature of the political figures being followed on Twitter

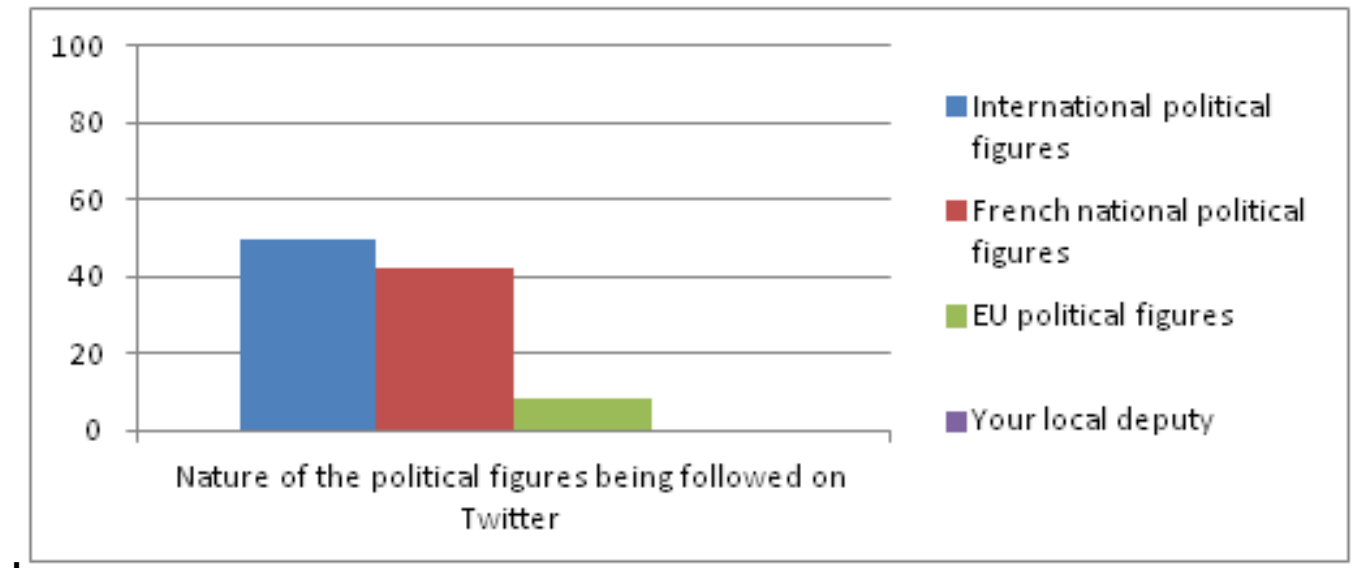

Source: Author 
Figure 5.1.6. Frequency of visits per week (Facebook and Twitter)

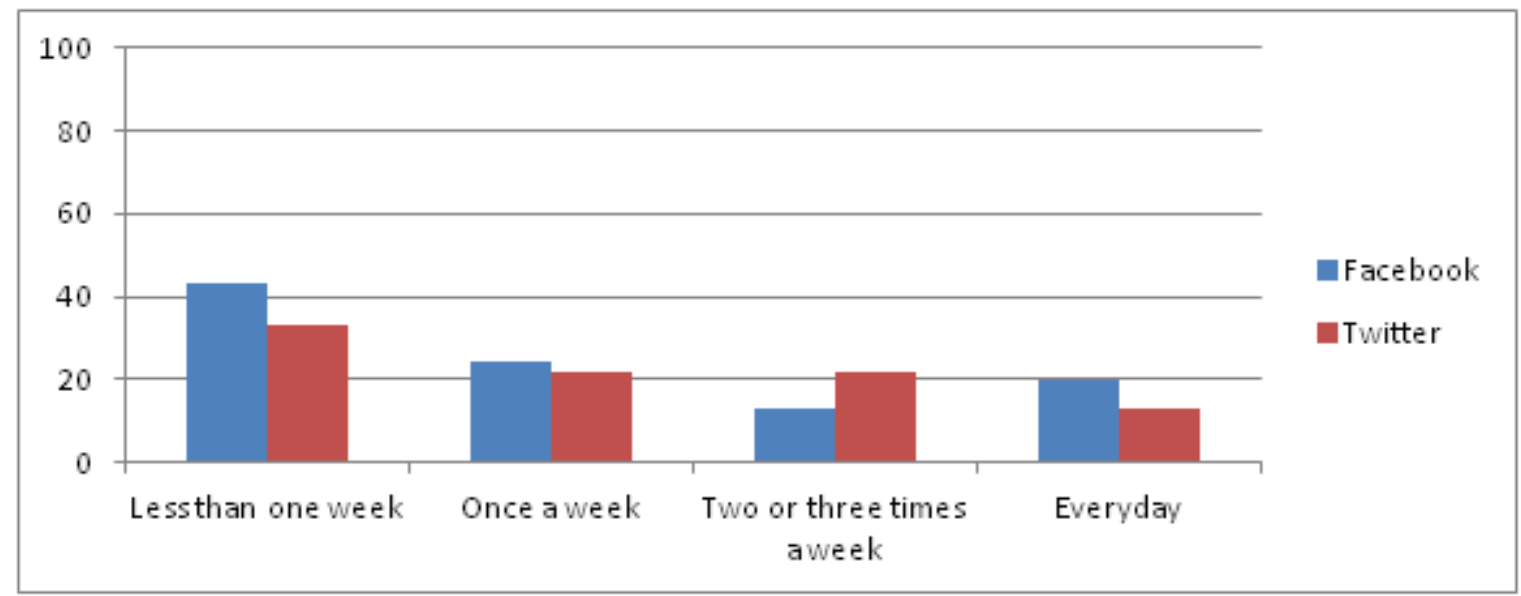

Source: Author

To sum up, one can firstly claim that a really large majority of the respondents hold a Facebook account. Among these Facebook users, 71.5\% declare to not follow one or several political figures, and when they do, they choose to follow renowned international or national politicians rather than local representatives. In regard to visit frequency, it is relevant to note that a small share of the people who actually follow politicians on Facebook check their pages every day and a large part of them consult them less than once a week. Secondly, people's answers indicate that a really low number of respondents use Twitter; but that, in contrast to Facebook, a bigger part of them do it for political purposes. Similarly to Facebook, they prefer to follow famous political figures rather than local deputies and tend to not visit these pages on a regular/daily basis. Hence, one can argue that using Facebook is significantly more popular among French citizens than using Twitter. Moreover, although Twitter's users may be more prone to follow and visit political pages than Facebook users, such behaviour remains really unusual and limited for both cases. Our findings suggest that there is, furthermore, a 
greater tendency for people following these pages to be interested in famous national or international figures rather than in local representatives - despite the fact that the former may actually govern farther away from the respondents' constituency or country. Overall, these results tend to validate our first hypothesis (H1): "a small part of French citizens use social media to learn more about the opinions and activities of their representatives".

\subsubsection{Testing the second hypothesis $(\mathrm{H} 2)$ : Transparency in social media, a} successful tool to connect the citizens with their representatives?

The second part of this study intends to test our second hypothesis ( $\mathrm{H} 2)$; "social media has not succeeded in informing the public and in creating a new type of interaction between represented and representatives". For that purpose, we examine how French citizens evaluate this process of transparency of politicians in social media; whether they think it is an effective and useful tool, and whether they feel that it has managed to bridge the gap between them and their representatives. We firstly asked our respondents whether they deem that following these pages gives them relevant information about the different activities of their representatives (Q9). We obtained rather balanced results; with $23.5 \%$ answering with a Yes, $28 \%$ with a No, and $49 \%$ admitting not having any opinion (Figure 5.2.1). Quite similar results were found to the next question - "Do you feel that following these pages allow you to better understand what happens at French Assemblée Nationale" (Q10) - for which 16.5\% of the respondents decided to tick the box "Yes" and 38.5\% the box "No" (Figure 5.2.2). We then tried to tackle the issue from a different perspective. Accordingly, we asked our panel of participants whether they think that politicians usually take people's interventions and discussions on social media into consideration (Q11). The answers collected were in line with our previous 
findings and indicated a high degree of scepticism and disregard from the public (Figure 5.2.3). To finish our analysis, we decided to ask, as a final question, whether transparency in social media has succeeded in creating a new link between citizens and representatives (Q12). Not surprisingly, our findings demonstrate that a majority of the people (46\%) do not believe that transparency in social media generates today a new type of interaction between citizens and representatives (Figure 5.2.4).

Figure 5.2.1. Do you feel that following these pages gives you relevant information about the activites of your representative(s)

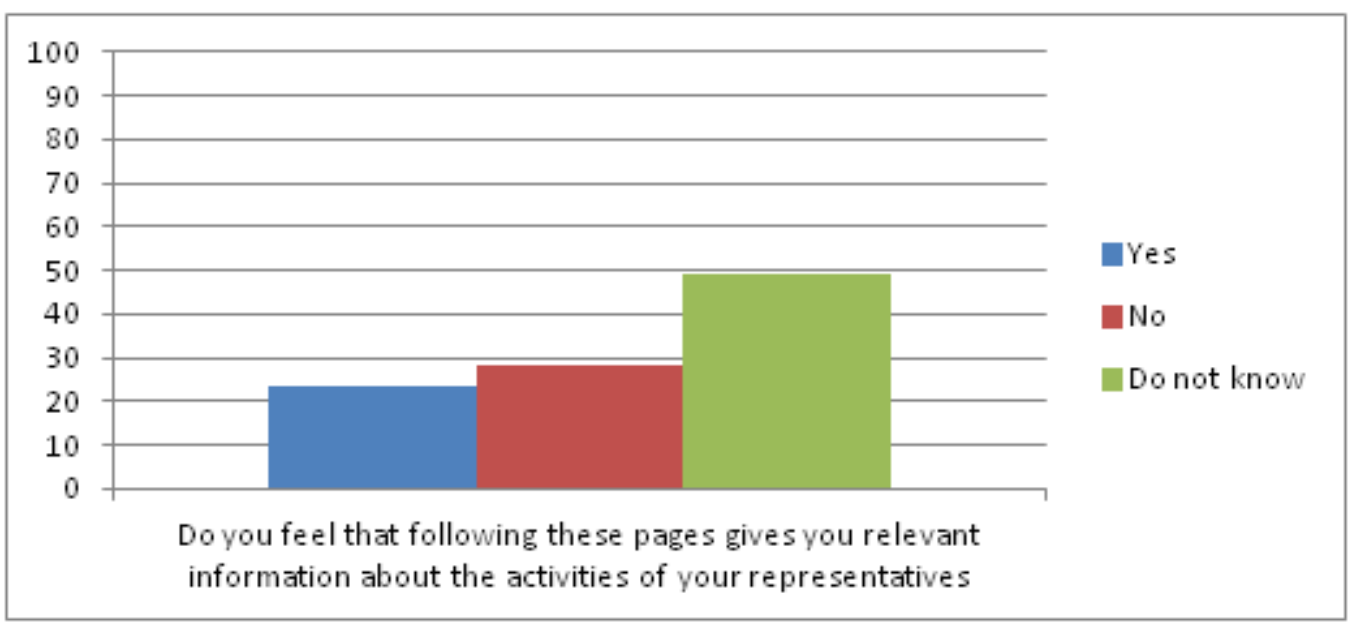

Source: Author

Figure 5.2.2. Do you feel that following these pages allow you to better understand what happens at the "Assemblée Nationale" 
MaRBLE Research Papers | Edition 2016 | Volume III

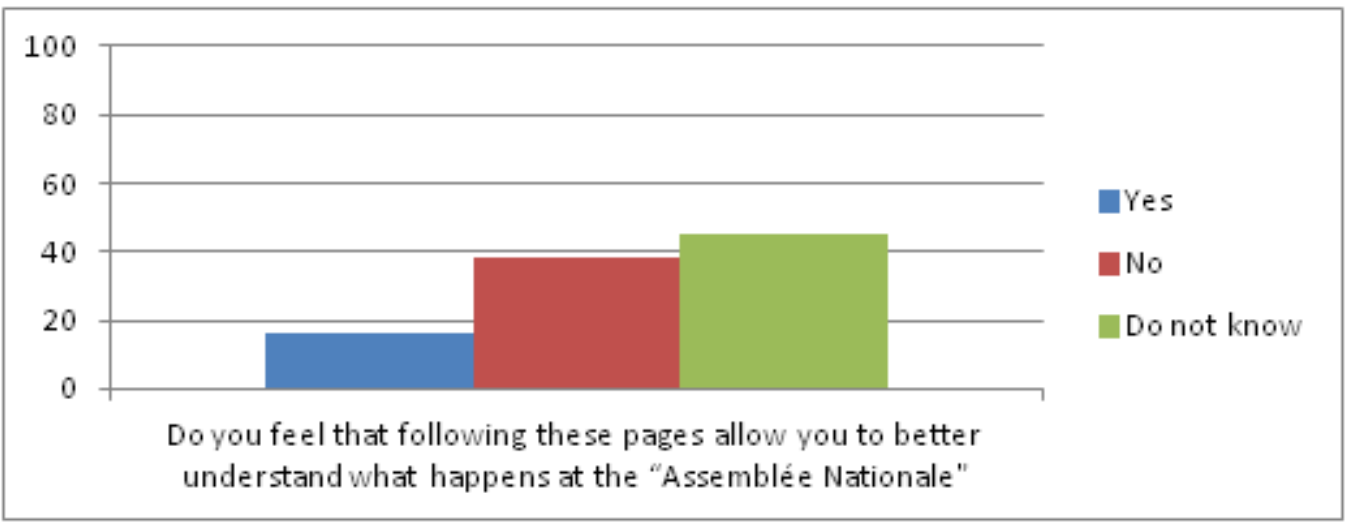

Source: Author

Figure 5.2.3. Do you think politicians usually take people' intervention on social media into consideration

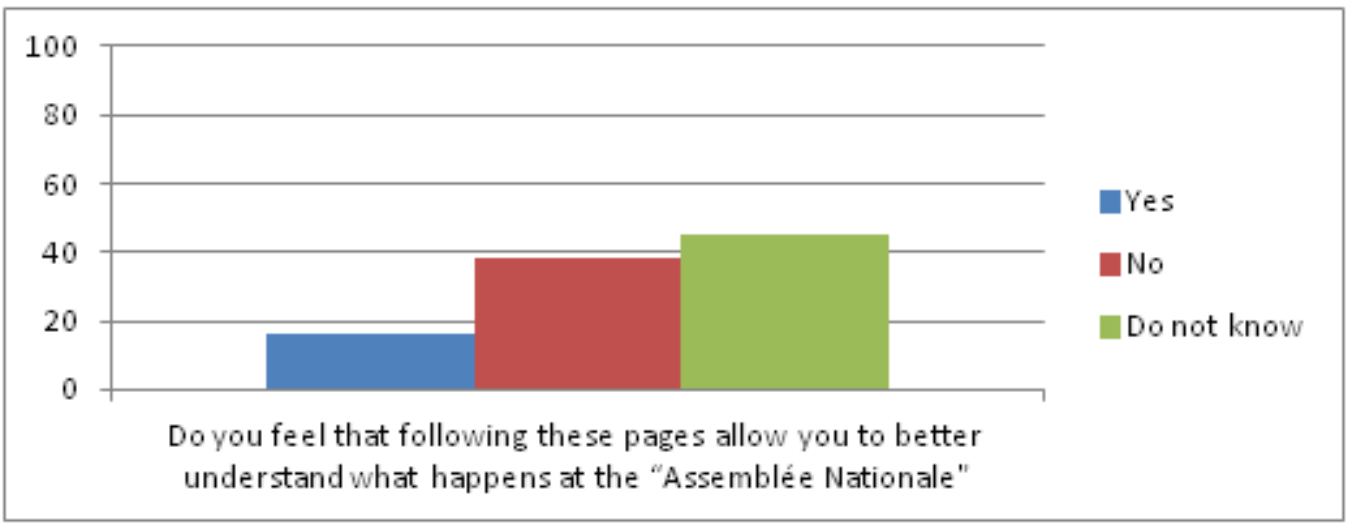

Source: Author

Figure 5.2.4. Do you feel that following these pages has succeeded in creating a link between you and your representatives? 


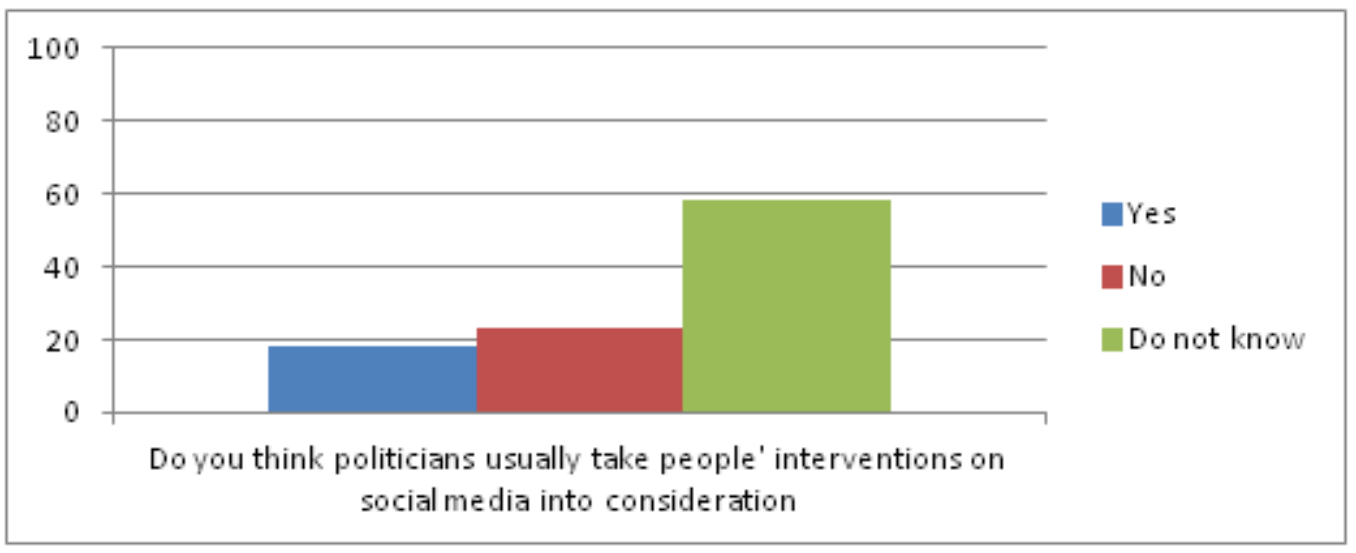

Source: Author

Putting it all together, our findings suggest that most of the people surveyed tend to poorly evaluate the process of political transparency in social media as it stands today. First of all, regarding efficiency, they deem that following politicians' pages fails to provide citizens with relevant information on the activities and opinions of their representative. They judge, moreover, this information not to be sufficient to understand the ins and outs of the French assembly, and think that this process of transparency often resembles a one way road, in which politicians tend to ignore people's suggestions and remarks. Second of all, only a few respondents believe that following politicians on a social media creates a new interaction between citizens and representatives. This supports the view that Facebook and Twitter users are highly sceptical about the idea of transparency of politicians in social media and corroborates our second hypothesis (H2): "social media has not succeeded in informing the public and in creating a new type of interaction between represented and representatives". 


\subsection{Conclusion}

Today, reengaging citizens into politics and restoring their trust towards political institutions is an important issue. For many scholars, the advent of internet - and most particularly of social media - has offered new possibilities to modernize representative democracy and revolutionize citizens' relationship with their political representatives. This networked revolution implies the creation of new means of transparency by which citizens would potentially be able to inform themselves about the activities and opinions of their representatives and by the same way directly interact with them. In light of this argument, this paper tackles the issue of transparency of French representatives on Facebook and Twitter, and addresses the following research question "Does transparency in social media succeed in re-connecting French representatives with their citizens?".

The first part of this paper examines the general usage of Facebook and Twitter by French deputies. This analysis indicates that both social networks are conventionally used by French deputies for political purposes yet, with a greater amount of followers gathered on Twitter's pages and a greater extent of information generally shared on Twitter. Only a few of these posts turn out to be about non-political matters and a really large part of these Facebook and Twitter's publications tend to either inform the public about politicians' legislative and political activities or to bring light on certain political positions. Furthermore, our study displays that these publication sometimes generate - on both social media - a high amount of public reactions. However, the really low amount of direct interactions between users and politicians, and the poor nature of the discussions these publications provoke - most particularly on Twitter - imply that transparency in social media does not fully achieve its purpose and fails to create new links between the French citizens and their deputies. 
The second part of this paper addresses the issue through a different angle by looking at how people assess this process of political transparency in social media. In this regard, we decided to conduct a small, conveniencebased survey among the French population. The first part of the survey shows that, while most of the people surveyed hold a Facebook account, only a minority revealed to be Twitter's users. Moreover, only a limited part of those using social media declared to follow one or several politicians on Facebook or Twitter. When they do, they furthermore admit to hardly visit their pages and read their publications. Secondly, a majority of the people surveyed disclosed to not believe that transparency in social media can help them understand better the complexity of political affairs. A large part of them feels that politicians tend to ignore people's suggestion and comments on social media, and that following politicians on social media does not succeed in creating a new kind of relationship with their representatives.

These results suggest that, although French politicians use social media to share political information, most French citizens do not take the time to consult it. This can be due to many factors; either because they deem the information shared not to be sufficiently relevant or trustworthy, or simply because they are not present on social media. Additionally, they show that, when people actually react to politicians' publications, it is often done in a clumsy or aggressive way, and rarely leads to any direct interactions between the public and the politicians.

It is important to note that this paper also contains a few limitations. To start, one must mention that, due to the limited resources and time span that were allocated for the completion of this study; we only managed to collect 150 answers to our questionnaire. Although this number is sufficient to draw some conclusions and have an idea of the general trends on the issue, it would be relevant to extent this research and therefore survey a larger amount of people. Moreover, it would be interesting to look at 
MaRBLE Research Papers | Edition 2016 | Volume III

generational schemes and examine whether the young generations apprehend the issue of transparency in social media in a more positive fashion than their elders. This could be done by performing a correlation analysis of the data extracted from the questionnaire. 